\title{
Transient ST Segment Elevation in a Patient with COVID-19 and a Normal Transthoracic Echocardiogram
}

\author{
Tareq Tuaima ${ }^{1}$, Abdulhalim J Kinsara ${ }^{2}$, Amtalkhaliq Alrajawi ${ }^{1}$, Hassan H Allam ${ }^{1}$, Shadwan Alfakih ${ }^{1}$ \\ ${ }^{1}$ King Abdullah Medical Complex, Ministry of Health, Jeddah, Saudi Arabia \\ ${ }^{2}$ Ministry of National Guard-Health Affairs, King Saud Bin Abdulaziz University for Health Sciences, COM-WR, King Abdullah International Medical \\ Research Center, Jeddah, Saudi Arabia
}

Received: 24/07/2020

Accepted: 04/08/2020

Published: 07/09/2020

How to cite this article: Tuaima T, Kinsara AJ, Alrajawi A, Allam HH, Alfakih S. Transient ST segment elevation in a patient with COVID-19 and a normal transthoracic echocardiogram. EJCRIM 2020;7: doi:10.12890/2020_001913.

Conflicts of Interests: The Authors declare that there are no competing interests.

This article is licensed under a Commons Attribution Non-Commercial 4.0 License

\section{ABSTRACT}

The effect of COVID-19 on the cardiovascular system still needs to be clarified. Patients can develop a spectrum of cardiac diseases, from mild myocarditis to acute coronary syndrome with an impaired systolic fraction. We describe an interesting case of transient ST segment elevation in a COVID-19 patient admitted to ICU for severe respiratory distress syndrome. During his stay in ICU, the patient developed transient ST segment elevation in inferior-lateral leads which promptly resolved without requiring any additional invasive and/ or pharmacological treatment.

Transthoracic echocardiography showed a preserved ejection fraction without any regional abnormalities and the rise in enzyme biomarkers was insignificant. The case highlights the importance of avoiding invasive procedures in this subset of patients to reduce both patient complications and medical staff exposure. Careful evaluation including echocardiogram and second-line examinations should be performed before invasive and aggressive treatment is undertaken.

\section{KEYWORDS}

ST segment elevation, COVID-19, echocardiogram

\section{LEARNING POINTS}

- Transient ST elevation may occur in critically ill COVID-19 patients.

- Early recognition is important to avoid unnecessary intervention or thrombolytic therapy.

\section{INTRODUCTION}

Severe acute respiratory syndrome coronavirus 2 (SARS-CoV-2) infection causes coronavirus disease 2019 (COVID-19) ${ }^{[1]}$. Cardiac involvement in patients infected with COVID-19 is increasingly recognized and may indicate a poor outcome ${ }^{[2]}$. Acute coronary syndrome is a recognized event in this population, however, ST segment elevation on electrocardiogram (ECG) has mainly been described in patients with COVID-19-related acute myocarditis and severe left ventricular systolic dysfunction ${ }^{[2-5]}$. We describe a case of transient ST segment elevation in a patient with a preserved left ventricular ejection fraction (LVEF). Our goal is to raise awareness of this aspect of cardiovascular involvement in COVID-19 and prevent unnecessary thrombolysis and catheterization. 


\section{CASE DESCRIPTION}

A 58-year-old male patient with no known chronic medical illness, was admitted to a local hospital with a 4-day history of fever and associated dyspnoea. At presentation, his pulse was 85 beats per minute, blood pressure was 110/72 mmHg, and he had tachypnoea with 30 breaths per minute and a low oxygen saturation (80\%) on room air. On day 3 of admission, the patient's respiratory symptoms deteriorated and he was intubated, mechanically ventilated, and norepinephrine was prescribed for hypotension. Subsequently, he was transferred to our intensive care unit (ICU). The patient's chest $x$-ray is shown in Fig. 1.

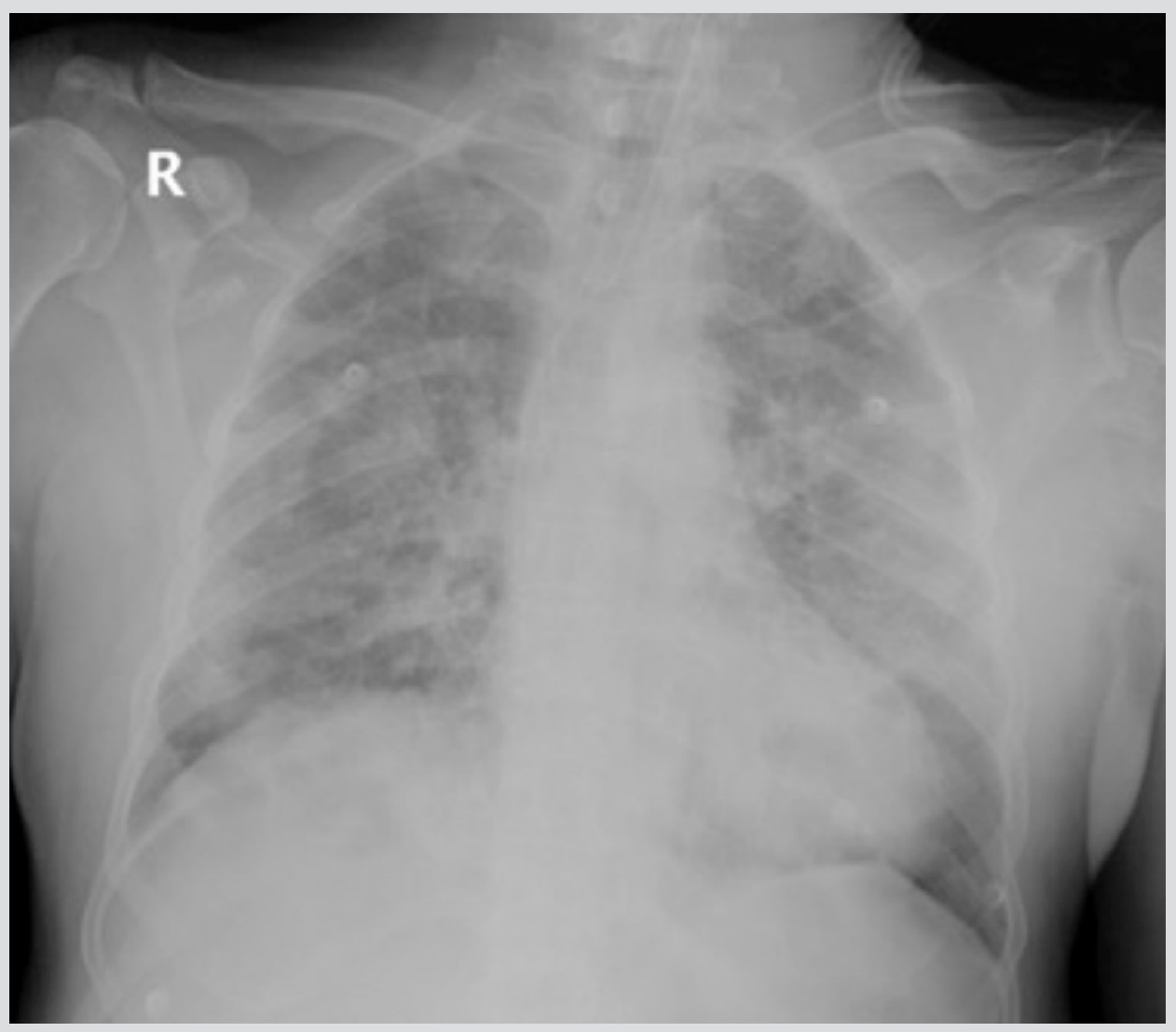

Figure 1. Chest $x$-ray of the patient showing diffuse opacities bilaterally, consistent with acute respiratory distress syndrome

A baseline ECG showed non-specific T wave changes, with no demonstration of acute ischaemic changes or arrhythmia (Fig. 2). The patient's baseline troponin I was $0.05 \mathrm{ng} / \mathrm{ml}$. On day 2 in ICU, the patient's hypoxia worsened, requiring maximum ventilatory support and sedation. A repeat ECG indicated ST segment elevation in leads V2-V6, lead III and aVF (Fig. 3). As the patient had life-threatening respiratory failure, pharmacotherapy was planned. However, after the administration of anti-platelet loading doses and anticoagulant (intravenous heparin was initiated), the ECG ST elevation resolved on the monitor before thrombolytic therapy was provided. The 12-lead ECG was repeated to confirm this finding, and thrombolytic therapy was cancelled (Fig. 4). A transthoracic echocardiogram revealed the absence of any regional wall motion abnormality with normal left ventricular (LV) systolic function, and adequate diagnostic value. The patient was started on aspirin $81 \mathrm{mg}$ and clopidogrel $75 \mathrm{mg}$; the other medications included oseltamivir (part of our COVID-19 treatment protocol), linezolid and meropenem (as secondary infection or sepsis was suspected), norepinephrine, midazolam and fentanyl. Repeated troponin I measurements, scheduled 8 hours apart, were $0.056 \mathrm{ng} / \mathrm{ml}, 1.4 \mathrm{ng} / \mathrm{ml}$ and $1.3 \mathrm{ng} / \mathrm{ml}$, respectively. The day 2 troponin I was $1.2 \mathrm{ng} / \mathrm{ml}$, but D-dimer was significantly elevated at $8.2 \mathrm{mg} / \mathrm{l}$ (normal $0.0-0.5$ ). There were no clinical findings to suggest pericarditis. The April 2020 Consensus Statement from the Society for Cardiovascular Angiography and Interventions, American College of Cardiology, and American College of Emergency Physicians states: 'In COVID-19 confirmed patients with severe pulmonary decompensation (adult respiratory distress syndrome) or pneumonia who are intubated in the intensive care unit and felt to have an excessively high mortality, consideration for compassionate medical care may be appropriate'. Our patient was fell into this category and hence did not undergo a coronary angiogram. 

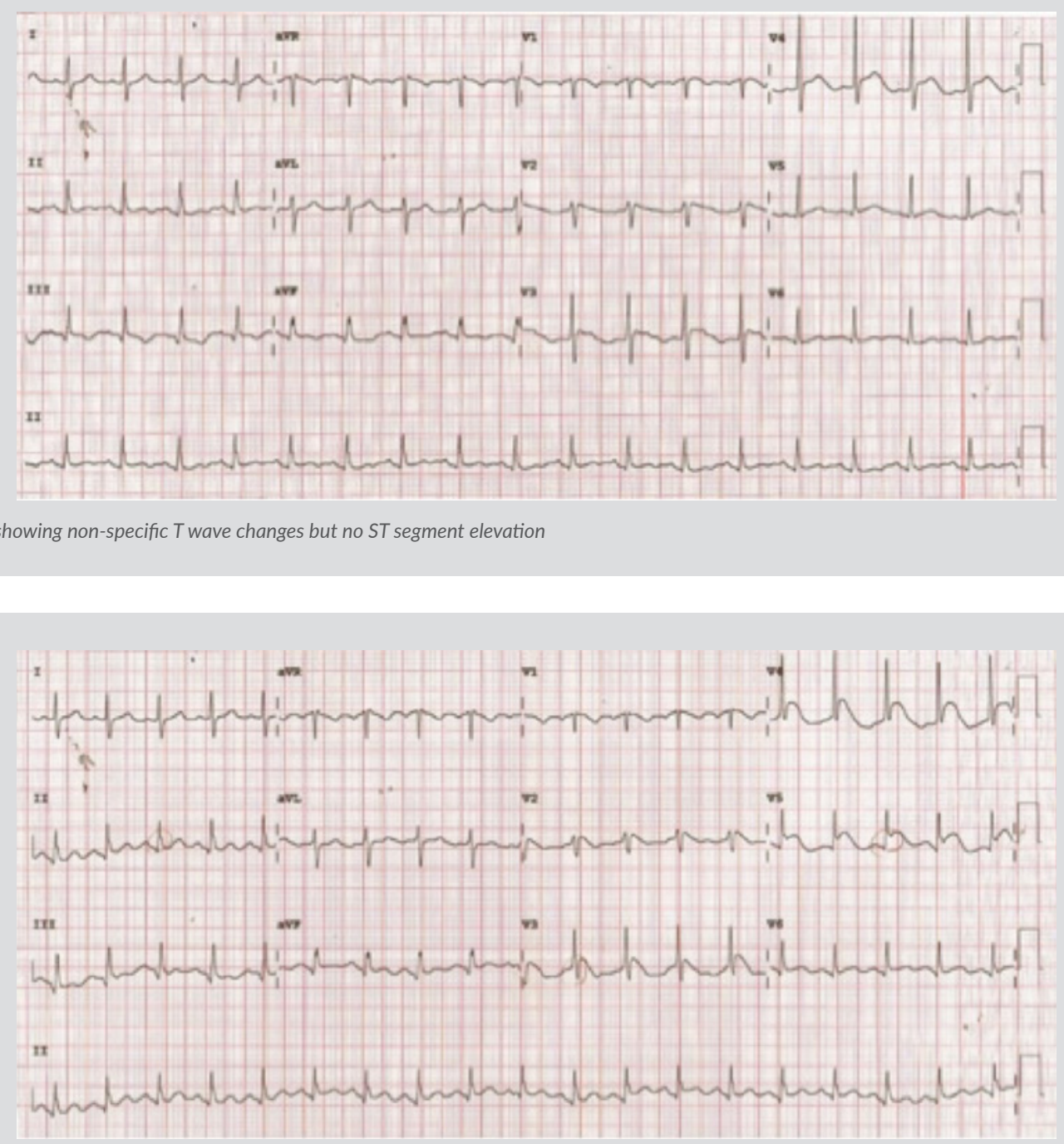

Figure 3. ECG showing ST segment elevation in leads V2-V6, lead III and aVF

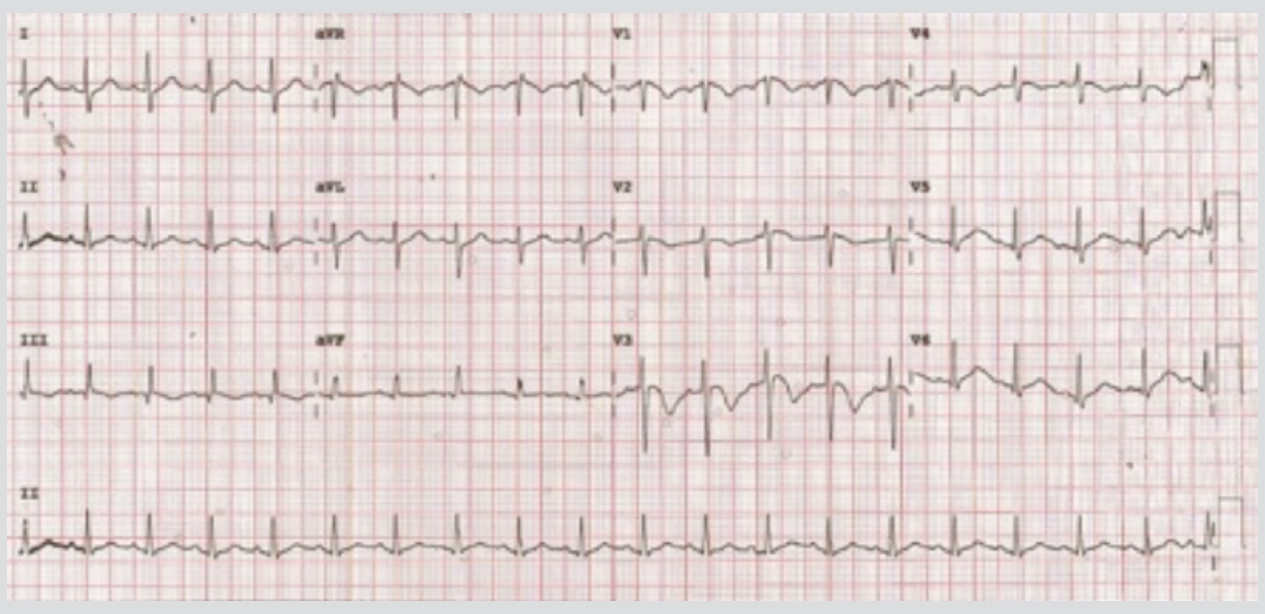

Figure 4. Repeat ECG within an hour showing resolution of ST elevation without any intervention 


\section{DISCUSSION}

We described a case of transient ST elevation on ECG in a patient with normal LV function and COVID-19. The majority of previous cases of COVID-19-related ST elevation involved patients with fulminant myocarditis and a severely reduced LVEF ${ }^{[2-5]}$. These cases add to our understanding of cardiac involvement in active COVID-19, especially given the uncertainty of proceeding with invasive coronary angiography and the need to balance staff exposure with patient benefit ${ }^{[6]}$.

The pathogenesis of acute myocardial injury is unknown. Myocardial injury in patients with COVID-19 could be due a single factor or a combination of microthrombi, coronary spasm, plaque rupture, direct endothelial/vascular injury, hypoxic damage or cytokine storm ${ }^{[7,8]}$. Our patients could have focal myocarditis from SARS-CoV-2 infection or a type 2 myocardial infarction from severe hypoxia and hypotension ${ }^{[4,5]}$. Acute coronary syndrome type 1 also remains a possibility given the systemic proinflammatory stimulation and hypercoagulability in patients with acute COVID-199,10]. Our patient did not have the typical risk features of Prinzmetal ST elevation, such as female gender, relatively younger age, and smoking. The echocardiogram during the attack did not show regional wall motion abnormalities (RWMA), nor was there a rise in troponin. This favours COVID-19 endotheliitis and endothelial dysfunction, which can be associated with coronary spasm and thrombosis ${ }^{[8]}$.

A multidisciplinary approach should be used to manage the patient and the guidelines of the American College of Cardiology's Interventional Council and the Society of Cardiovascular Angiography and Intervention should be followed for any reperfusion therapy ${ }^{[6]}$.

The recommended treatment during the COVID-19 pandemic is primary percutaneous coronary intervention (PCI); however, personal protection equipment should be available, with intensive decontamination after each case. In advanced respiratory failure or a high risk of mortality, a modified approach with compassionate care is a possible option ${ }^{[6]}$. Similarly, additional tests such as COVID status or echocardiography should be carefully considered. All patients have to be managed as though possibly infected with COVID-19 from the first contact.

\section{CONCLUSION}

Transient ST elevation may occur in critically ill COVID-19 patients and requires watchful management.

\section{REFERENCES}

1. Fried JA, Ramasubbu K, Bhatt R, Topkara VK, Clerkin KJ, Horn E, et al. The variety of cardiovascular presentations of COVID-19. Circulation 2020;141(23):1930-1936.

2. Shi S, Qin M, Shen B, Cai Y, Liu T, Yang F, et al. Association of cardiac injury with mortality in hospitalized patients with COVID-19 in Wuhan, China. JAMA Cardiol 2020;5(7):802810.

3. Hu H, Ma F, Wei X, Fang Y. Coronavirus fulminant myocarditis saved with glucocorticoid and human immunoglobulin. Eur Heart J 2020 Mar 16 . doi: $10.1093 /$ eurheartj/ehaa190 [Epub ahead of print].

4. Inciardi RM, Lupi L, Zaccone G, Italia L, Raffo M, Tomasoni D, et al. Cardiac involvement in a patient with coronavirus disease 2019 (COVID-19). JAMA Cardiol 2020;5(7):1-6.

5. He J, Wu B, Chen Y, Tang J, Liu Q, Zhou S, et al. Characteristic ECG manifestations in patients with COVID-19. Can J Cardiol 2020 Mar 29. doi: 10.1016/j.cjca.2020.03.028 [Epub ahead of print].

6. Welt FGP, Shah PB, Aronow HD, Bortnick AE, Henry TD, Sherwood MW, et al. Catheterization laboratory considerations during the coronavirus (COVID-19) pandemic: from ACC's Interventional Council and SCAI. J Am Coll Cardiol 2020;75(18):2372-2375.

7. Bangalore S, Sharma A, Slotwiner A, Yatskar L, Harari R, Shah B, et al. ST-segment elevation in patients with Covid-19 - a case series. N Engl J Med 2020;382(25):2478-2480.

8. Mosleh W, Chen K, Pfau SE, Vashist A. Endotheliitis and endothelial dysfunction in patients with COVID-19: its role in thrombosis and adverse outcomes. J Clin Med 2020;9(6):E1862.

9. Courand PY, Harbaoui B, Bonnet M, Lantelme P. Spontaneous coronary artery dissection in a patient with COVID-19. JACC Cardiovasc Interv 2020;13(12):e107-e108.

10. Asif T, Ali Z. Transient ST segment elevation in two patients with COVID-19 and a normal transthoracic echocardiogram. Eur J Case Rep Intern Med $2020 ; 7(5): 001672$. 